This document has been approved for public release and sale; its distribution is unlimited.

VISUAL HORIZONTAL PERCEPTION IN RELATION TO OTOLITH FUNCTION* Earl F. Miller II, Alfred R. Fregly, and Ashton Graybiel

Bureau of Medicine and Surgery

MR005.04-0021

NASA Order R-93

\author{
Released by \\ Captain J. W. Weaver, MC USN \\ Commanding Officer
}

23 December 1966

*This research was conducted under the sponsorship of the Office of Advanced Research and Technology, National Aeronautics and Space Administration.

NAVAL AEROSPACE MEDICAL INSTITUTE

NAVAL AEROSPACE MEDICAL CENTER PENSACOLA, FLORIDA 32512 


\section{SUMMARY PAGE}

\section{THE PROBLEM}

To determine the influence of the otolith organs on visual localization of the horizontal during nineteen positions of body tilt within \pm 90 degrees of gravitational vertical.

\section{FINDINGS}

The mean constant and variable errors shown by a group of fifteen normal persons and a group of ten deaf subjects with bilateral labyrinthine defects were compared. High test-retest reliability was demonstrated for both groups. Although the general pattern of results was similar for the two groups, the labyrinthine-defective group was found to be more variable and manifested greater E- and A-effects in their settings in several of the tilt positions. A significantly larger E-effect was observed in those subjects (L-Ds) with little or no ocular counterroll. 


\section{INTRODUCTION}

In a recent study (12) the visual localization of a group of normal subjects was compared with that of a group of deaf persons with known bilateral labyrinthine defects. Each subject was required to set a luminous line to the gravitational horizontal when he was placed in 1) an erect, 2) a recumbent (left side), and 3) an inverted head (body) position. In the absence of visual reference cues, significant intergroup differences were found in the settings made when the subject was in the erect and in the recumbent positions. That these differences were quantitative, i.e., the normals showed less errors, rather than qualitative emphasized the contribution of the sensory receptors in the otolith organs. Other studies comparing the visual localization of normal and labyrinthine-defective (L-D) subjects tended to confirm this conclusion $(8,11)$.

The present study, in which both normal and L-D subjects were also tested, was designed to determine the influence of the otolith organs on the visual localization of the horizontal at $10^{\circ}$ intervals of body tilt through $90^{\circ}$ leftward and rightward from the gravitational vertical. It is well known that in this range of body tilt, a subject will usually manifest a bias in making settings first by undercompensating (E-phenomenon) (14), then overcompensating (A-phenomenon) (1). One theory that has been advanced to explain at least partially the cause of the E-phenomenon is the ocular counterrolling reflex (7) associated with head tilt. Inasmuch as that reflex is greatly suppressed in L-D subjects (9), it was taken into account in this study.

\section{PROCEDURE}

\section{SUBJECTS}

Fifteen healthy male subjects ranging in age from 24 to 35 years formed the normal group; ten deaf subjects aged 20 to 47 years served as the comparison group. In addition to their deafness these latter subjects had lost completely, or nearly completely, function of the semicircular canals and otolith organs (Table I) as measured by caloric $(3)$, ataxia $(4,5)$, and counterrolling (7) test methods.

\section{APPARATUS}

The apparatus used for tilting a seated subject and measuring his visual judgments of horizontality was identical to that of a previous study in which a detailed description was reported (13).

The apparatus consisted of a hydraulically powered chair which could be tilted and held stationary in any given position within $\pm 90^{\circ}$ from gravitational upright. The subject was secured in the chair with seat belt and shoulder harness. 


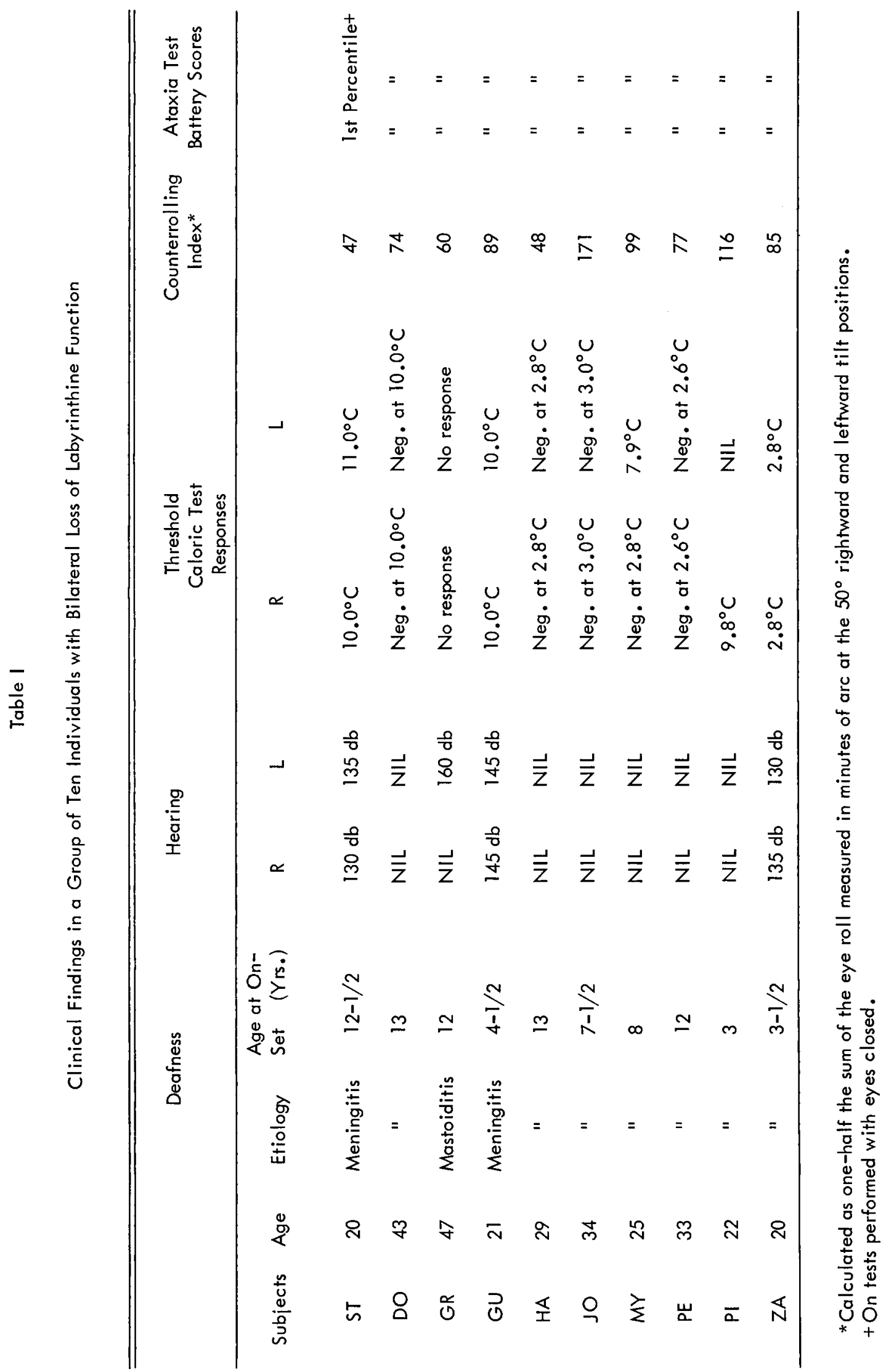


A target, which was positioned approximately 36 inches in front of him, consisted of a dimly illuminated line of collimated light on a dark background. The subject could rotate the target clockwise or counterclockwise about its center by means of a knob provided at his right hand. A similar control was available to the observer seated behind the subject at the control panel. This panel contained circular protractor scale readouts of the angular position of the target and tilt chair which could be read within \pm 0.25 degree. The entire testing system was placed in a light tight room. A buzzer signal heard by the normal subjects and felt on the fingertips by the deaf subjects provided all the necessary communication between subject and observer.

\section{METHOD}

After subject was secured upright in the tilt chair, his left eye was covered by an opaque patch. Then the target was adjusted so that, to the subject, it appeared to be centered within its cylindrical housing. The room lights and target light were then turned off. The observer at the control console slowly tilted the subject at the rate of approximately $1 \mathrm{deg} / \mathrm{sec}$ to the first of nineteen pre-selected but randomly scheduled body positions $(0, \pm 10, \pm 20, \pm 30, \pm 40, \pm 50, \pm 60, \pm 70$, $\pm 80, \pm 90$ degrees). After thirty seconds in the tilted position the target was illuminated and the subject was signalled to make his first setting. Upon making his setting the subject signalled the observer, who then turned off the target light, offset the line (direction and magnitude were random), then turned on the target light for subject's next setting. This procedure was repeated until ten settings were recorded. The subject was then tilted to the second randomly scheduled body position, which was in the opposite direction. Leftward/fightward tilting was alternated with the exception that the final position within each block of ten trials was always upright for all subjects. To determine test-retest reliability, all subjects were re-tested by the same procedure within one to ten days.

\section{RESULTS AND DISCUSSION}

Test-retest reliability as computed by correlating (Spearman rank order) the constant error curve configuration of the first experimental test session with that of the second experimental test session was 0.94 for the normal and 0.81 for the L-D subjects.

The mean constant and variable errors of the two groups of subjects as measured for the various tilt positions (first experimental test session) are shown in Figures 1 and 2, respectively. At each tilt position the means of the first three and last three of the ten settings of each subject group at each tilt position are plotted as coded points, together with the respective mean of all ten settings indicated as the group curve. No constant error is shown in Figure 1 for the 0 -degree tilt position inasmuch as the mean setting at upright (Point of Subjective Horizontal) was used as 


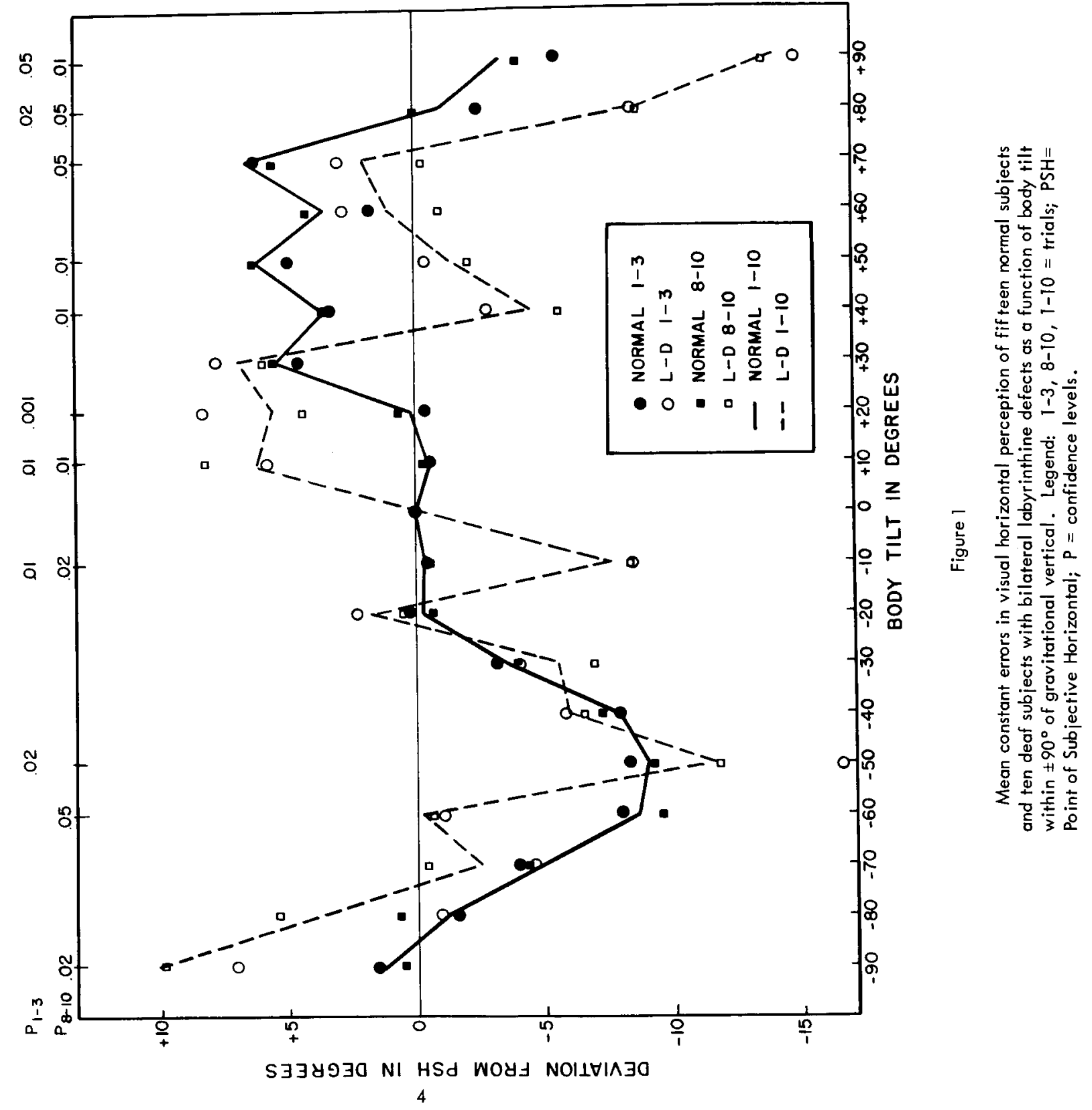




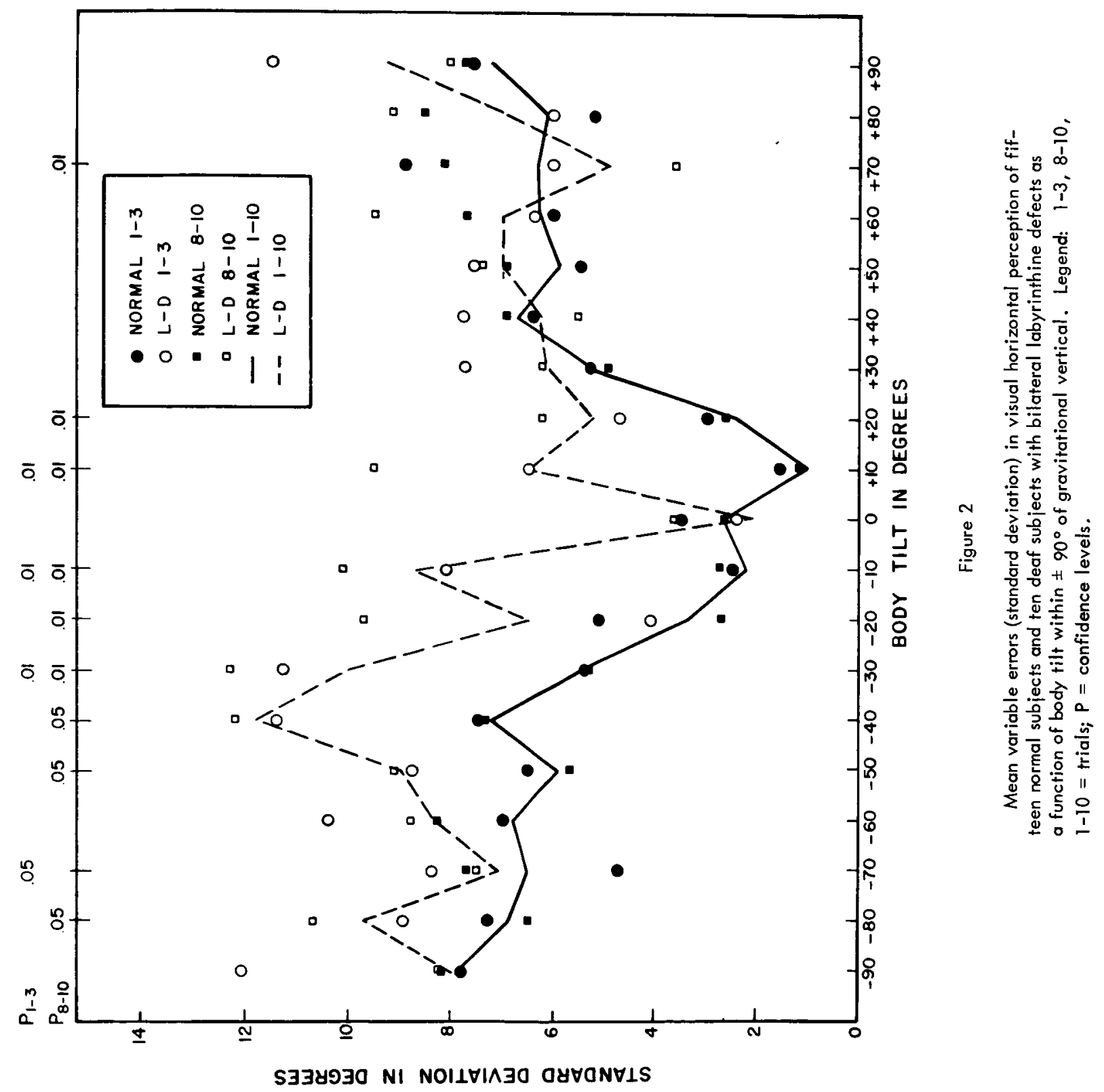


a basis for calculating the deviation of the mean setting of all other positions. This was done to eliminate any procedural or equipment bias that may have existed, for example, variations in the way the subject was secured in the tilt chair. The judgments of the normal group were typical for normal subjects (13) and revealed the characteristic A- and E-phenomena in fairly symmetrical fashion for the clockwise (+) and counterclockwise (-) direction of tilt. The maximum E-bias (4.6 to 8.4 degrees) occurred at the \pm 30 to 50 degrees of tilt. Beyond this tilt the bias tended to re verse rather slowly and became an A-bias when the longitudinal axis of the body approached horizontal .

The group of L-D subjects revealed the same general pattern of localization with bodily tilt, but their settings deviated more in the E- and A-directions than did those of the normal group. The variable error (standard deviation) of the settings tended to increase with increasing bodily tilt in both groups but to a greater extent in the L-D subjects, particularly when they were tilted toward their left side. In the L-D subjects significant changes in the constant and variable errors occurred in certain tilt positions within the time required to make ten settings and were observed in more positions of tilt and to a greater degree. At the top of Figures 1 and 2 , the confidence $(P)$ levels of the significant $(P \leq .05)$ intergroup differences in the first three and last three settings are indicated above the corresponding degree of body tilt. Between the first $(1-3)$ and last $(8-10)$ three groups of measurements the number of positions of tilt at which significant intergroup differences in constant errors were seen increased from six to nine; for such differences in variable error the number of positions increased from four to nine.

The most likely explanation of the intergroup differences observed is that they represent principally the influence of the otolith organs, which appear to provide effective cues for visual localization since subjects without normally functioning otoliths were significantly less accurate (greater A- and E-deviations) and more variable in visual localization. However, visual localization is based also upon nonotolithic factors, which in certain body positions are as effective alone as in combination with those of otolithic origin. No significant intergroup differences were found in more than half the tilt positions with in the 180 -degree range tested, and, with few exceptions, the L-D subjects using primarily nonotolithic cues manifested a general pattern of response which was qualitatively similar to that of the normal subjects. Notable intergroup differences occurred with small $\left( \pm 10^{\circ}\right)$ and large $\left( \pm 80^{\circ}, \pm 90^{\circ}\right)$ angles of tilt, which is a finding consistent with other studies $(11,12)$. These results indicate that when the L-D subject is tilted slightly from his usual upright position, the available cues impress an exaggerated sense of tilt, whereas at or near recumbency these cues lead to his underestimation of tilt. A visual localization task in positions near upright is now being explored as a simple means of differentiating normal and otolithic defective individuals. 
Based upon recent visual localization studies carried out on normal individuals during weightlessness (6), the greater variability in settings shown by the L-D subjects in the present study probably reflects the interplay of the active nonotolithic sensory inputs rather than a reduction in sensory information caused by the functional loss of the otolith organs.

Although temporal changes in constant errors and in variable errors were found in the present study, further investigation of the visual localization of L-D subjects as a function of time duration at a given tilt position is required to define possible "adaptation" effects of nonotolithic receptors. When nonotolithic inputs are combined with vestibular (otolithic) information, as indicated by the settings of normal subjects, adaptation effects upon visual localization do not appear to occur in any typical pattern: The A-phenomenon may increase, decrease, or remain unchanged when observed during long periods in a tilted position $(10,14)$. In related studies $(2,15)$ it was shown that after a relatively short initial lag period following a sudden change in the magnitude as well as the direction of resultant force, the oculogravic illusion in normal subjects developed quickly to a peak and then underwent no systematic change during test periods up to four hours, whereas L-D subjects demonstrated only a gradual change in the illusion and required one-hour exposure to reach the magnitude shown by the normal subjects.

The possible influence of ocular counterrolling on the E- and A-phenomena (Figures 3 and 4 ) is depicted by the average value of ocular counterrolling measured in nine of the normal and all of the L-D subjects of this study. If the E-phenomenon were to be explained simply on the basis of ocular counterrolling and concomitant shift of the "horizontal retinal meridian," the pattern of counterrolling should mirror the E-effect; $i$.e., sums of the two curves should equal zero in normal subjects (Figure 3 ) and, essentially, be absent in the L-D subjects (Figure 4). It is apparent from these data plots that such a simple explanation is invalid since not only is the patterning of these two responses different in subjects with normal counterrolling values, but their E-deviations are equalled or exceeded by the L-D subjects. The elimination of the E-effect by manipulation of kinesthetic cues as reported for both normals and L-D subjects (16) demonstrates further the multiple basis of this visual phenomenon. 


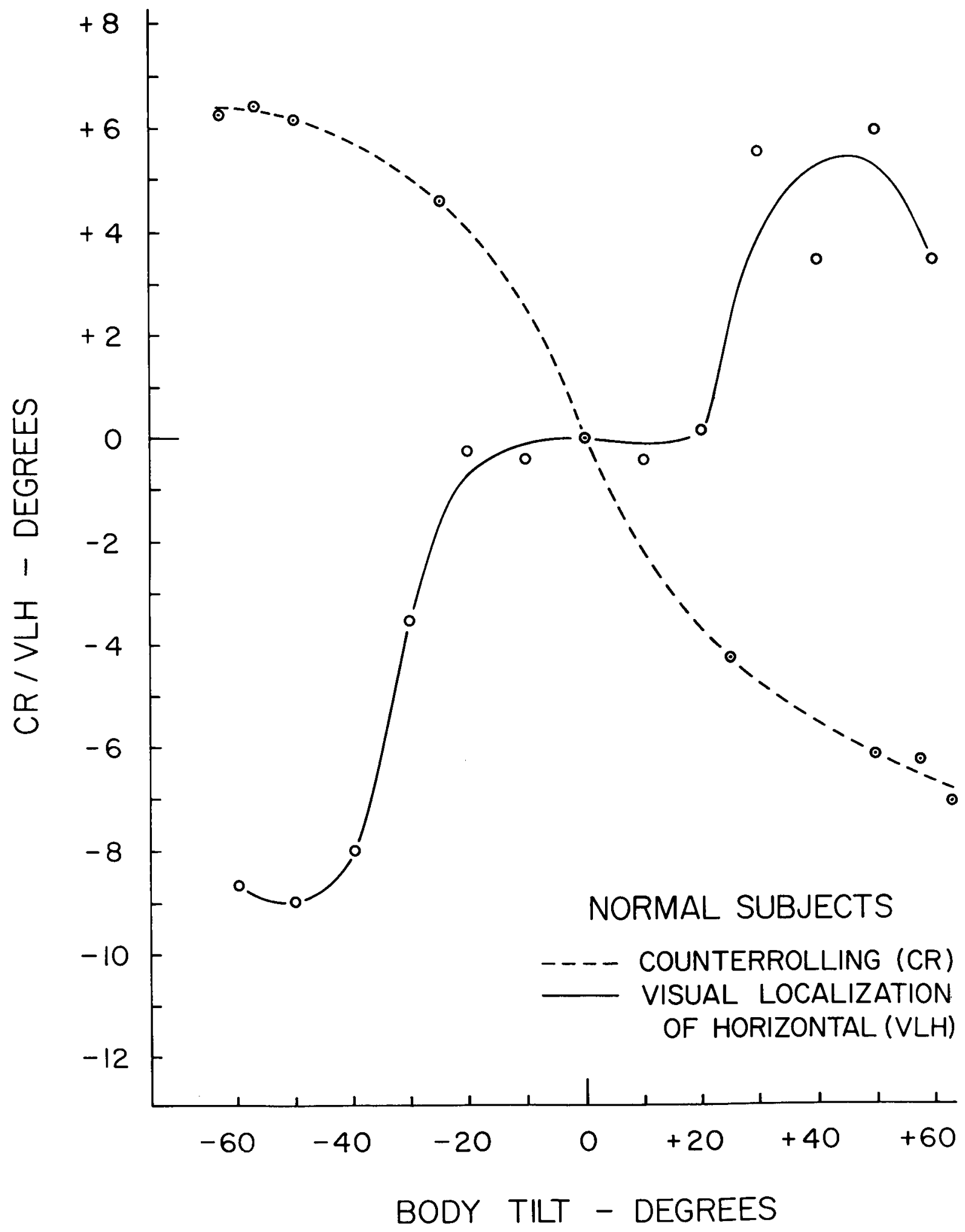

Figure 3

A comparison of counterrolling results and constant errors in visual horizontal localization of nine normal subjects as a function of body tilt within $\pm 60^{\circ}$ of gravitational vertical. 


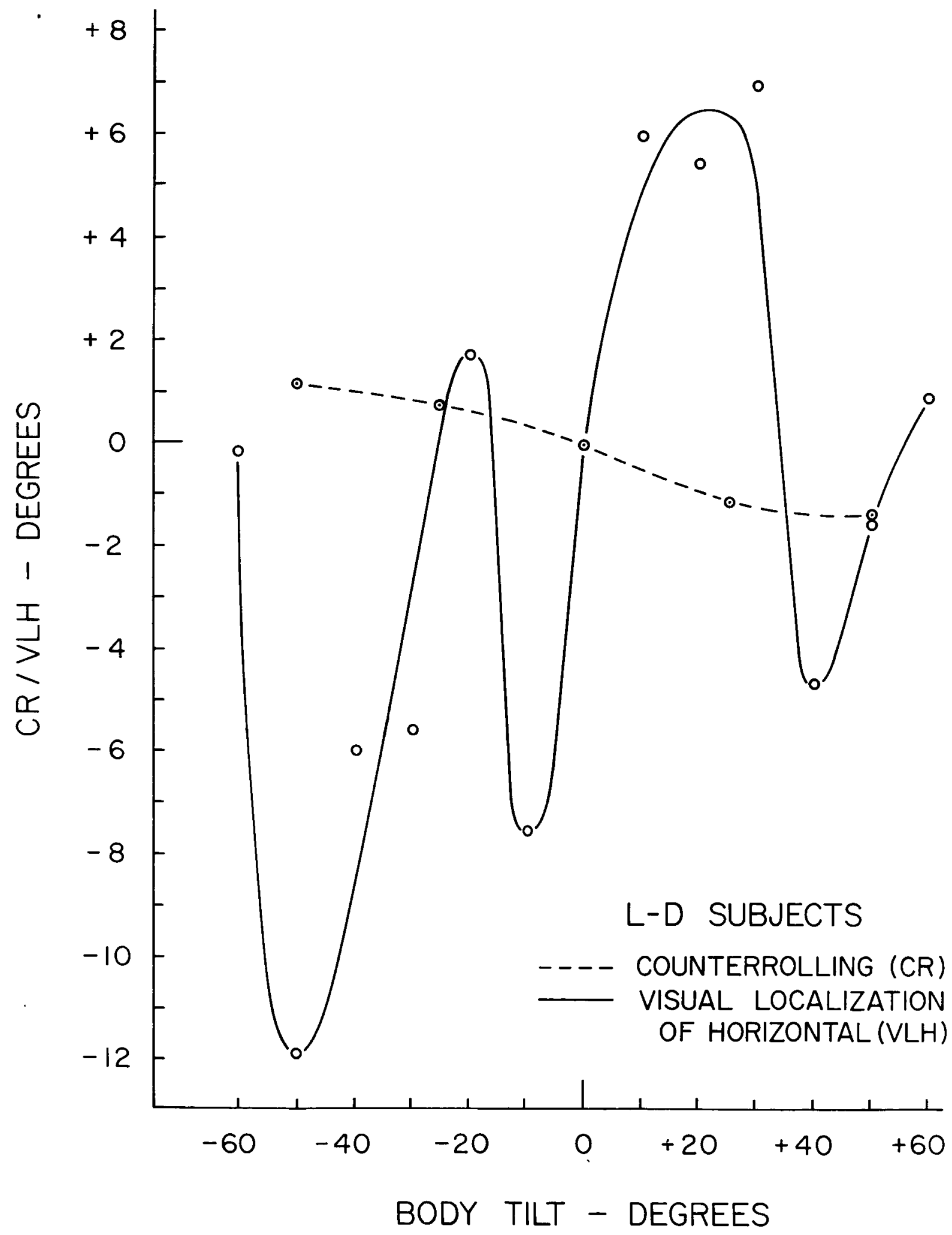

Figure 4

A comparison of counterrolling results and constant errors in visual horizontal localization of ten deaf subjects with bilateral labyrinthine defects as a function of body tilt within $\pm 60^{\circ}$ of gravitational vertical. 


\section{REFERENCES}

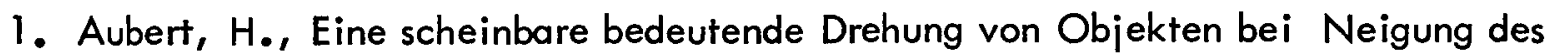
Kopfes nach rechts oder links. Virchows Arch., 20:381-393, 1861.

2. Clark, B., and Graybiel, A., Visual perception of the horizontal during prolonged exposure to radial acceleration on a centrifuge. J. exp. Psychol., 63:294-301, 1962.

3. McLeod, M. E., and Meek, J. C., A threshold caloric test: Results in normal subjects. NSAM-834. NASA R-47. Pensacola, Fla.: Naval School of Aviation Medicine, 1962.

4. Graybiel, A., and Fregly, A. R., A new quantitative ataxia test battery. Acta otolaryng., Stockh., 61:292-312, 1966.

5. Fregly, A. R., and Graybiel, A., An ataxia test battery not requiring the use of rails. NAMI-985. NASA R-93. Pensacola, Fla.: Naval Aerospace Medical Institute, 1966.

6. Graybiel, A., Miller, E. F. II, Billingham, J., Waite, R. E., Berry, C. A., and Dietlein, L. F., Vestibular experiments in Gemini flights V and VII. Aerospace Med., 38:360-370, 1967.

7. Miller, E. F. II, Counterrolling of the human eyes produced by head tilt with respect to gravity. Acta otolaryng., Stockh., 54:479-501, 1961.

8. Miller, E. F. II, and Graybiel, A., Comparison of autokinetic movement perceived by normal persons and deaf subjects with bilateral labyrinthine defects. Aerospace Med., 33:1077-1080, 1962.

9. Miller, E. F. II, and Graybiel, A., A comparison of ocular counterrolling movements between normal persons and deaf subjects with bilateral labyrinthine defects. Ann. Otol., 72:885-893, 1963.

10. Miller, E. F. II, and Graybiel, A., Rotary autokinesis and displacement of the visual horizontal associated with head (body) position. Aerospace Med., 34:915-919, 1963.

11. Miller, E. F. II, and Graybiel, A., Magnitude of gravitoinertial force, an independent variable in egocentric visual localization of the horizontal. J. exp. Psychol., 71:452-460, 1966.

12. Miller, E. F. II, and Graybiel, A., Role of the otolith organs in the perception of horizontality. Amer. J. Psychol., 79:24-37, 1966. 
13. Miller, E. F. II, Fregly, A. R., van den Brink, G., and Graybiel, A., $V i s u a l$ localization of the horizontal as a function of body tilt up to $\pm 90^{\circ}$ from gravitational vertical. NSAM-942. NASA R-47. Pensacola, Fla.: Naval School of Aviation Medicine, 1965.

14. Müller, G. E., Über das Aubertsche Phänomenon. Z. Sinnesphysiol., 49: Part II.,109-244, 1916.

15. Clark, B., and Graybiel, A., Perception of the visual horizontal in normal and labyrinthine defective subjects during prolonged rotation. Amer. J. Psychol., 79:608-612, 1966.

16. Clark, B., and Graybiel, A., The egocentric localization of the visual horizontal in normal and labyrinthine-defective observers as a function of head and body tilt. Percept. and Psychophys., 2:609-611, 1967. 
Security Classification

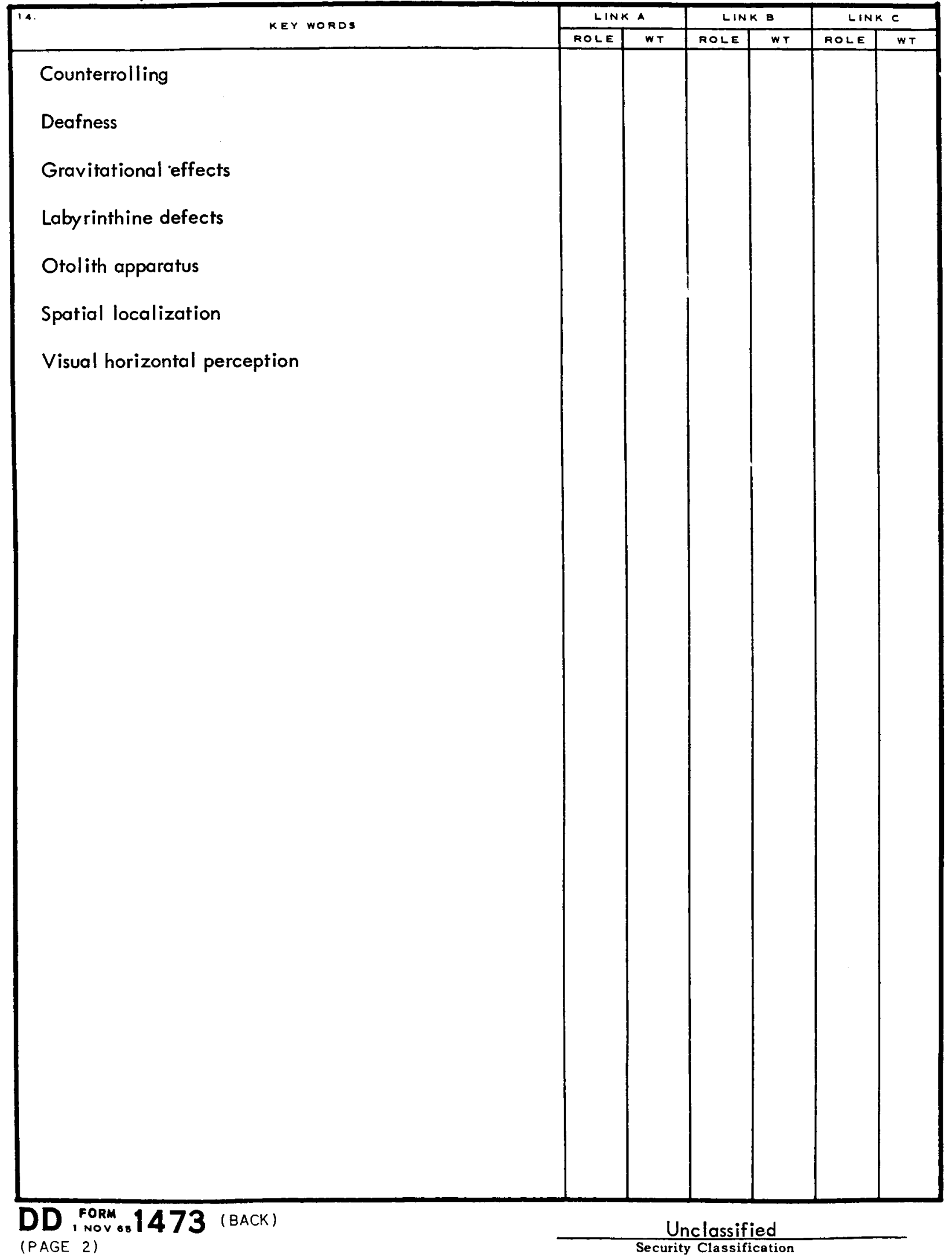


Unclassified

Security Classification

DOCUMENT CONTROL DATA - R \& D

serierity clasufication of title, body of abstract and indexing innotation nust be entered whon the overall report is classilfied

\begin{tabular}{|c|c|c|}
\hline $\begin{array}{l}\text { Naval Aerospace Medical Institute } \\
\text { Pensacola, Florida } 32512\end{array}$ & \begin{tabular}{|l} 
2a. REFO \\
UN \\
2b. GROL \\
$\mathrm{N} / \mathrm{A}$
\end{tabular} & $\begin{array}{l}\text { CURITY CLASSIFICATION } \\
\text { SSIFIED }\end{array}$ \\
\hline \multicolumn{3}{|c|}{ VISUAL HORIZONTAL PERCEPTION IN RELATION TO OTOLITH FUNCTION. } \\
\hline \multicolumn{3}{|c|}{$\begin{array}{l}\text { 4. DESCFIPTIVE NOTES (Type of report and inclusive dates) } \\
\mathrm{N} / \mathrm{A}\end{array}$} \\
\hline \multicolumn{3}{|c|}{ Earl F. Miller, II, Alfred R. Fregly, and Ashton Graybiel } \\
\hline $\begin{array}{l}23 \text { December } 66 \\
\text { 6. REPORT DATE }\end{array}$ & $\begin{array}{l}\text { 7a. TOTAL NO. OFPAGES } \\
12\end{array}$ & $\begin{array}{c}\text { 7b. NO. OF REFS } \\
16\end{array}$ \\
\hline $\begin{array}{l}\text { Ba. CONTRACT OR GRANT NO } \\
\text { R-93 } \\
\text { B. PROJECT NO. } \\
\text { MRO05.04-0021 }\end{array}$ & $\begin{array}{r}\text { 9A. ORIGINATOR'S REPORT } \\
\text { NAMI-989 }\end{array}$ & BER(S) \\
\hline c. & $\begin{array}{l}\text { 96. OTHER REPORT NO(S) } \\
\text { this report) } \\
141\end{array}$ & ther numbers that may be assigned \\
\hline
\end{tabular}

This document has been approved for public release and sale; its distribution is unlimited.

\begin{tabular}{l|l}
\hline 11. SUPPLEMENTARY NOTES & I2. SPONSORING MILITARY ACTIVITY
\end{tabular}

To determine the influence of the otolith organs on visually perceived direction of space the constant and variable errors of normal persons and deaf persons with bilateral labyrinthine defects during nineteen positions of body tilt within $\pm 90^{\circ}$ of gravitational vertical were compared. The general perceptual pattem was similar for the two groups, although that of the labyrinthine-defective group was found to be more variable, and greater E- and A-effects were manifested during several of the tilt positions. A significantly larger E-effect was observed in those subjects (L-Ds) with little or no ocular counterroll. 